\title{
O reconhecimento e as práticas cotidianas do poder e da autoridade
}

\author{
Recognition and the everyday practices \\ of power and authority
}

Luiz Gustavo da Cunha de Souza*

Resenha de:

McBRIDE: Cillian. Recognition. Cambridge: Polity Press, 2013.

Desde o debate entre Nancy Fraser e Axel Honneth (Fraser and Honneth, 2003) acerca dos conceitos de redistribuição e reconhecimento muitos comentários foram feitos sobre o tema. Poucos, porém, ambicionaram apresentar uma nova teoria social do reconhecimento de alcance tão longo quanto os respectivos modelos destes autores. Este passo foi dado por Cillian McBride. Ao mérito de sistematizar uma teoria do reconhecimento a partir daquilo que se poderia chamar de sua fenomenologia, o autor adiciona outro: ao decidir-se por contrapor os modelos de Honneth e Charles Taylor, McBride evita a estéril separação - bastante comum na literatura brasileira sobre o tema, a propósito ${ }^{1}$ - entre um modelo antropológico de lutas por cultura e outro modelo normativo de luta pelo desenvolvimento pessoal bem-sucedido. Uma de suas premissas é, pois, a de que reconhecimento não é um fenômeno psicológico como o define Fraser, mas normativo e relativo à capacidade humana de avaliar outros indivíduos à luz de uma série parâmetros normativos (McBride, 2013, p. 67). Daí que, a partir da constatação de que todos se

\footnotetext{
* Doutor em Sociologia pela Universidade Estadual de Campinas (Unicamp, Campinas, SP, Brasil). Bolsista de Pós-Doutorado da Alexander von Humboldt Stiftung na Goethe Universität e no Institut für Sozialforschung em Frankfurt, Alemanha <gustavo_cunhas@yahoo.com.br>.

${ }^{1}$ Uma exceção aqui é representada por Giovani A. Saavedra e Emil Sobottka (2009, p. 397), que notam que o debate entre Fraser e Honneth tem como pano de fundo uma leitura equivocada da americana sobre a teoria do alemão.
} 
importam com reconhecimento, McBride busque desdobrar três pressupostos: reconhecimento é um elemento da atividade (agency) humana (p.5); os modelos de Taylor e Honneth, que imaginam a luta política por reconhecimento como lutas pela correção de um deficit, não dão conta da complexidade das disputas por poder de que fazem parte estas lutas (p. 6); lutas por reconhecimento deveriam ser tomadas como lutas por autoridade normativa (p. 6).

O livro, parte da série Key concepts da editora Polity, é dividido em uma introdução e cinco capítulos que se assemelham a ensaios sobre formas em que reconhecimento incide sobre práticas cotidianas. No primeiro capítulo discutem-se as políticas de reconhecimento; no segundo, o conceito de respeito; no terceiro, a relação entre estima e distinção social; no quarto capítulo, justiça e reconhecimento e no quinto e último, as lutas por reconhecimento. Através deste percurso, McBride espera demonstrar como aqueles modelos de 'correção do deficit' acabam por apresentar imagens do reconhecimento purificadas de dimensões de conflito, de demandas concorrentes e de dilemas morais.

Em relação às políticas de reconhecimento, McBride compartilha das interpretações hegelianas de Taylor e Honneth quanto à necessidade de entender a formação da personalidade individual como um processo dialógico no qual o indivíduo acaba por descobrir seu próprio self. Deste modo, reconhecimento sempre será importante porque, quer se queira ou não, sempre será necessário lidar com o modo como se é tratado pelos outros (p. 13). O fato de que o desenvolvimento da personalidade individual se dá por meio da interação com outros sujeitos é o que move McBride a recusar a identidade cultural como o parâmetro para as políticas de reconhecimento, retomando aqui as conhecidas objeções à política de reconhecimento de particularidades, uma vez que os particularismos podem, também eles, representar formas de opressão à individualidade, de modo que os modelos de correção do reconhecimento deficitário não estariam aptos a apreender os desejos das minorias envolvidas nesta relação, bem como este modelo seria insensível à desigualdade de poder envolvida em associar a uma camada dominante ou majoritária o poder de atribuir ou retirar reconhecimento (p. 38). Nesta medida, o que McBride sugere que sejam tomados como parâmetros para as políticas de reconhecimento são, por um lado, a forma como um grupo deseja ser reconhecido e, por outro, a capacidade de outros grupos de realizar este desejo. Isso nos leva ao segundo capítulo, no qual é feita uma defesa do reconhecimento universal por meio do respeito. Ao contrário da estima social, respeito se refere a um tipo de relação social necessariamente dirigida a outra pessoa, percebida como uma portadora de um direito que deve ser estendido aos outros sem qualquer julgamento 
valorativo. Neste sentido, respeito estaria ligado ao reconhecimento de que os interesses de todos devem ser igualmente ouvidos (p. 49) e seria oposto às formas extremas de não-reconhecimento, como a 'morte social' imposta a escravos, uma vez que estes, sendo desprovidos de qualquer status moral, sequer poderiam ser objetos de malfeitos (p. 60).

Neste momento McBride parece ser vítima de certa confusão entre a normatividade do respeito e os fenômenos de opressão analisados, particularmente ao afirmar que, sendo a estima social uma avaliação particular sobre os méritos do outro, esta poderia ser atribuída a um escravo que não possua o status de pessoa. Em seu comentário sobre o livro, Onni Hirvonen (2015) chama a atenção para um primeiro ponto: esta estima não se direcionaria a uma pessoa, mas a uma coisa, não constituindo, portanto, uma relação de reconhecimento. Mais importante, porém, me parece ser o fato de que o próprio McBride (2013, p. 31) nota que, além de experiências psicológicas individuais, situações de subreconhecimento são também discursos baseados em contextos de esterótipos, prejuízos e expectativas que podem servir de base para a afirmação mesma de um grupo enquanto grupo. Neste caso, McBride estaria antes preso a uma leitura segundo a qual respeito seria o reconhecimento do direito (jurídico?) básico de ter a própria voz ouvida. Ao mesmo tempo, ele nota que esta forma igualitária de reconhecimento deve ser conjugada com uma outra, necessariamente distribuída de modo desigual, que é a estima social. Mais do que os problemas práticos ligados ao orgulho pessoal em um cotidiano de hierarquizações, vaidades e consumo, McBride nota que a luta por estima social pode se transformar em um problema ético na medida em que distinções sociais, no sentido weberiano, podem erigir desigualdades que não apenas hierarquizam grupos de indivíduos mas também os incentivam a estabelecer comparações depreciativas, quando ocupam posições mais vantajosas, ou práticas emulativas, quando se encontram em posições menos vantajosas (p. 88). Nesta medida, a luta por estima social é apenas uma faceta da luta mais ampla pelo estabelecimento ou pela manutenção de hierarquias, de modo que, para McBride, o conflito fundamental com o qual as teorias do reconhecimento deveriam se ocupar não se dá entre universalidade e diferença, mas entre igualdade e distinção hierárquica, algo que os modelos corretivos do reconhecimento tenderiam a ignorar (p. 102). Como resposta a este dilema, McBride assume que um modelo de teoria da justiça que se proponha a enfrentar a problemática levantada pelas teorias do reconhecimento deveria apenas se ocupar com o reconhecimento do respeito básico, pois seria possível defender formas legítimas de subreconhecimento. Isso porque estimar não é algo que se escolha (p. 123). No entanto, se não é um caso de escolha, a 
negação da estima ou a humilhação deliberada o são. Assim, se a atribuição de estima não é um objeto das teorias da justiça, parece um exagero afirmar que nenhuma dimensão do conceito importe. Ainda que sua fenomenologia das relações de reconhecimento termine por chamar atenção para toda uma gama de práticas que escapam aos modelos normativos do reconhecimento, a solução de McBride infelizmente não se revela diferente daquelas já formuladas por Honneth, Taylor e mesmo Fraser: o reconhecimento do respeito seria uma maneira de contrabalançar o poder dos grupos privilegiados (p. 131).

$\mathrm{O}$ ceticismo de McBride quanto à possibilidade de um modelo de teoria do reconhecimento baseado na conciliação de conflitos se estende também ao capítulo final de seu livro, sobre a importância da luta por reconhecimento. Aqui o autor retoma a ideia de que reconhecimento importa porque 'identidade' não é algo transparente ou autêntico, mas o resultado de interações intersubjetivas. A intenção, porém, difere em um ponto decisivo daquela necessidade da intersubjetividade identificada por Honneth e Taylor, na esteira de Hegel, como um elemento normativo do desenvolvimento bemsucedido da personalidade individual. O que faz da perspectiva de McBride um passo além de ambos estes autores é exatamente o fato de que ele interpreta a luta por reconhecimento também como uma necessidade prática: o que está em jogo é a autoridade sobre nossas próprias autointerpretações e sobre as expectativas normativas que temos quanto aos outros e que eles têm sobre nós (p. 136). Daí que McBride considere que sua concepção sobre o tema do reconhecimento deva ser considerada 'interacionista' em oposição à concepção 'desenvolvimentista' defendida por Honneth. Exemplar de como ambas concepções se diferenciam talvez sejam as críticas que McBride dirige à forma como Honneth entende os efeitos dos processos de reconhecimento sobre a personalidade dos sujeitos. Por um lado, McBride afirma que a concepção honnethiana considera que, uma vez desenvolvidas as capacidades individuais para a autonomia e autorrealização, a luta por reconhecimento evidentemente continua a desempenhar um papel importante, mas Honneth não é claro sobre qual seria este papel, já que não dá qualquer atenção à dimensão interativa após o processo de desenvolvimento da personalidade (p. 139). Por outro lado, ao tratar das experiências de subreconhecimento e injustiça, McBride afirma que Honneth supõe que as autorrelações positivas construídas por meio de experiências de reconhecimento possam ser destruídas. Para McBride, porém, esta afirmação soa exagerada, na medida em que isso suporia, também, que os sujeitos são recipientes passivos da forma como são tratados por outros (p. 64). A partir deste último ponto McBride desenvolve, ainda que de forma apressada, uma interessante ideia sobre a importância daquilo que ele chama 
de "reconhecimento virtual", isto é, a justificação de expectativas normativas frente a uma comunidade imaginária que possa substituir o ambiente hostil no qual estas expectativas são inicialmente desrespeitadas. Mais do que a defesa de uma ética do reconhecimento centrada em critérios de respeito e reconhecimento da voz de cada um, como proposta ao final do livro, me parece que este tema merece um desenvolvimento mais cuidadoso, dado que conceitos como 'imaginário' ainda despertam pouco interesse entre pesquisadores do reconhecimento, apesar de sua importância.

Tudo dito, pois, o instrumental aqui apresentado por McBride me parece oferecer uma grande contribuição às teorias do reconhecimento em dois sentidos: porque nos chama a atenção para a importância cotidiana do que pensamos e vivenciamos sobre reconhecimento e também porque procura situar esta importância dentro das disputas por poder que estruturam as sociedades modernas. Neste sentido talvez não seja exagerado dizer que esta é a mais interessante adição ao debate sobre reconhecimento desde o debate entre Fraser e Honneth. $\mathrm{Ou}$, como costumam dizer nas ilhas britânicas: Brilliant!

\section{Referências}

FRASER, Nancy; HONNETH, Axel. Redistribution or recognition? A politicalphilosophical exchange, London: Verso, 2003.

HIRVONEN, Onni. Recognition: between politics and anthropology. Res Publica, v. 21 , n. 1 , p. $105-109,2015<10.1007 /$ s11158-014-9261-y>.

McBRIDE, Cillian. Recognition, Cambridge: Polity Press, 2013.

SAAVEDRA, Giovani A.; SOBOTTKA, Emil A. Discursos filosóficos do reconhecimento. Civitas, v. 9, n. 3, p. 386-401, $2009<10.15448 / 1984-7289.2009 .3 .6898>$.

Recebido em: 17 ago. 2015

Aprovado em: 1 dez. 2015

Autor correspondente:

Luiz Gustavo da Cunha de Souza

Institut für Sozialforschung

Seckenberganlage 26

60325 Frankfurt am Main, Germany 